\title{
Violence and depressive symptoms during pregnancy in BRISA cohort: using structural equation modeling approach
}

Sabrina Varão Oliveira Ribeiro 1

https://orcid.org/0000-0001-8807-639X

Rosângela Fernandes Lucena Batista 2

D https://orcid.org/0000-0002-1529-0165

Marizélia Rodrigues Costa Ribeiro 3

https://orcid.org/0000-0003-4289-4527

Kivania Carla Pessoa 4

https://orcid.org/0000-0001-5046-0994

Vanda Maria Ferreira Simões 5

https://orcid.org/0000-0001-8351-1348

Felipe Pinheiro de Figueiredo 6

https://orcid.org/0000-0001-8616-0483

Heloisa Bettiol 7

https://orcid.org/0000-0001-8744-4373

1,2,4,5 Departamento de Saúde Pública. Universidade Federal do Maranhão. Rua Barão de Itapary, 155. São Luís, MA, Brasil. CEP: 65020-070. E-mail: sabrinavarao@yahoo.com.br

3 Departamento de Medicina III. Universidade Federal do Maranhão. São Luís, MA, Brasil.

6 Departamento de Neurociências e Ciências do Comportamento. Universidade de São Paulo. Ribeirão Preto, SP, Brasil.

7 Departamento de Puericultura e Pediatria. Universidade de São Paulo. Ribeirão Preto, SP, Brasil.

\section{Abstract}

Objectives: to analyze associations among violence against pregnant women, depressive symptoms during pregnancy and maternal depression symptoms.

Methods: a sample of 1,139 mothers was conducted on a prenatal cohort study in the municipality of São Luis in Brazil. Psychological and physical violence against pregnant women were measured by the World Health Organization Violence Against Woman. Depressive symptoms during pregnancy were measured by the Escala de Depressão do Centro de Estudos Epidemiológicos (CES-D) (Depression Scale for Epidemiological Studies Center) and maternal depression symptoms were measured by the Edinburgh Postnatal Depression Scale (EPDS). The conceptual model of the structural equation modeling contained socioeconomic situation, social support, psychological and physical violence and depression during pregnancy as determinants of the maternal depression symptoms.

Results: maternal depression symptoms were more frequently reported by pregnant women who suffered psychological violence (Standardized Coefficient, $S C=0.256$; $p$-value, $p<0.001$ ), physical violence (SC $=0.221$ $p<0.001)$ and those who presented depressive symptoms during pregnancy $S C=0.322, p<0.001)$. Depressive symptoms during pregnancy mediated the effects on physical and psychological violence on maternal depression.

Conclusions: pregnant women who were submitted to psychological and physical violence and presented depressive symptoms during pregnancy frequently reported more of having maternal depression symptoms.

Key words Violence against women, Pregnancy, Depression 


\section{Introduction}

Depression is the most common mental disorder during pregnancy and the main risk factor for perinatal depression. Some studies have suggested that depression during pregnancy tends to persist during the postpartum period in about half the cases. 1

Approximately $10 \%$ of the pregnant women and $13 \%$ of the women during the first year of postpartum experience some type of mental disorder, especially depression and anxiety in high income countries. ${ }^{2}$ A meta-analysis systematic review showed a $5.9 \%$ rate of mental disorders during pregnancy and a $19.8 \%$ rate in the immediate postpartum period in middle and low income countries, but when the symptoms were self-reported, the percentages were lower (13.4\%) compared to the diagnostic evaluation $(21.7 \%)$.

Low socioeconomic level, low schooling level and a previous history of mental disorders were associated with mental disorders during the first year of postpartum. ${ }^{2}$

Violence against pregnant women can affect their physical and mental health, social and working life, as well as their ability to take care of themselves and their children. ${ }^{3}$ A meta-analysis systematic review of 67 publications, 12 of which were longitudinal studies showed that violence during pregnancy is associated to higher scores for depressive symptoms during pregnancy and postpartum period. 4

Standardized questionnaires in identifying depression are useful to monitor mental health both at individual and populational level. The Edinburgh Postnatal Depression Scale (EPDS), a 10 item scale developed by Cox et al. 5 to measure depression in women during the postnatal period and has proved to be useful in evaluating women. ${ }^{6}$ The use of the EPDS is in favor of its easy and rapid application. The high clinical value and the epidemiological scale have been confirmed by several studies and its validation has been performed in different countries, especially by applying on postpartum women. ${ }^{7-9}$

Although the associations between violence and depression during pregnancy are acknowledged, no studies reporting how these entities interact in order to determine postpartum depression were detected. In order to respond this question, the present study proposed a conceptual model using structural equation modeling in order to analyze the influence of physical and psychological violence against pregnant women and depressive symptoms during pregnancy on postpartum depression symptoms (Figure $1)$.

\section{Methods}

\section{Study design}

This is a cohort study using the cohort data entitled as "Fatores Etiológicos do Nascimento Pré-Termo e consequências dos Fatores Perinatais na Saúde da Criança: Coortes de Nascimentos em Duas Cidades Brasileiras - BRISA" Etiological Factors on Preterm Birth and Consequences on Perinatal Factors in Child Health: Birth Cohorts in Two Brazilian Cities - BRISA"). The data were collected in two stages: during the prenatal period (stage 1) to measure violence and during the child's second year of life (stage 2) to investigate the outcome of maternal depression symptoms.

\section{Study Location}

São Luís is the capital in the State of Maranhão, a city whose population was $1,014,837$ inhabitants in 2010. The city is located in one of the poorest regions in the country, and its Human Development Index (HDI) in the year 2010 was 0.768 , occupying the 249th position among the Brazilian municipalities. 10

\section{Participants and Sample}

A convenience sample was obtained during the prenatal period due to the impossibility of obtaining a representative random sample of pregnant women in the population of São Luís.

Pregnant women who were assisted in the prenatal and public service and planned their childbirth in the municipality of São Luís were invited to participate in the prenatal BRISA Cohort by following the criteria: a) have undergone an obstetrical ultrasound examination before the $20^{\text {th }}$ week of pregnancy, b) gestational age of 22 to 25 weeks at the moment of data collecting, and c) have a singleton fetus.

A total of 1,447 pregnant women in the prenatal phase were interviewed from February 2010 to June 2011. According to the objective of the present investigation, one pregnant woman was excluded because she did not answer the questions about violence and maternal depression, with a final sample consisting of 1,446 women.

At the end of prenatal data collection, the women received a participation card containing information about other schedules for data collection (at birth and on the child's second year of life) and they were instructed to communicate to the investigators that they belonged to the cohort study as soon as they arrived at the hospital for the childbirth. In this study, the data collected at birth were not used. 
Theoretical association model on violence during pregnancy and maternal depression symptoms in BRISA cohort. São Luís - MA, 2010-2013.

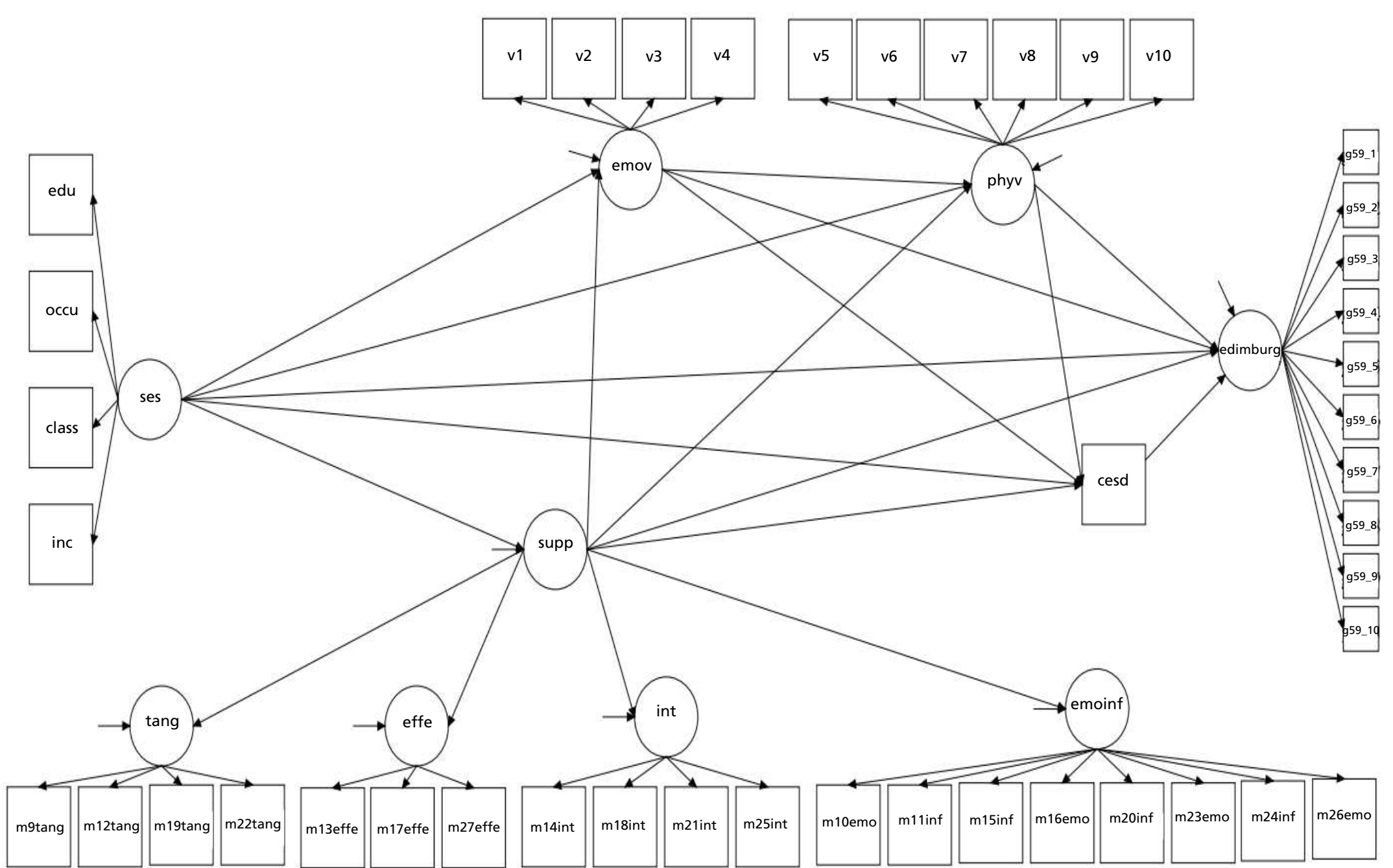


For the data collection on the children's second year of life, the mothers were invited by telephone contact to arrive at the Hospital Universitário Materno Infantil (HUMI) (Mother-Child University Hospital) for a new interview held from Monday to Saturday, when the children were in the age range of 15 to 36 months old. If they did not arrive on the scheduled day, they were invited again and a new date was rescheduled. If they refused to participate, their decision was respected. When the telephone contact was not possible, a motorcycle messenger properly identified wearing a shirt with the logotype of the project, actively searching for these mothers on the basis of their home address. Even after the telephone contact and a scheduled appointment, some mothers did not appear at the hospital (HUMI). As a last approach, the interviewers were sent to the mothers' home who had not come for the evaluation and the mothers who had stated that it would be impossible for them to come, could answer the questionnaires.

The questionnaire of stage 2 was standardized and answered, after the consent, by the mother or by a responsible guardian of the child by means of an interview. They also answered a self-applied questionnaire to collect various types of information, such as questions referring to postpartum depression symptoms.

The follow-up period data were collected from March 2011 to March 2013, a total of 1,151 mothers were evaluated and a total of 1,139 mothers responded the EPDS.

\section{Instruments for data collection}

Two questionnaires elaborated by the research coordination department were used in stage 1 of this present study: Prenatal Interview Questionnaire for the study on socioeconomic and demographic variables (age, marital status, the pregnant woman and the head of the family schooling, the Brazilian Economic Classification, and family income) and Self-Applied Prenatal Questionnaire from which information on violence, depression and social support during pregnancy were extracted.

The Self-Applied Maternal Mental Health Questionnaire was used in stage 2 (second year follow-up) in order to obtain information about postpartum depression symptoms. This questionnaire was also prepared by the research coordination department.

\section{Theoretical model and variables}

In the conceptual model (Figure 1), the socioeconomic situation occupied the most distal position, followed by the variables on social support, psycho- logical violence, physical violence and depressive symptoms during pregnancy, which determined the outcome regarding the postpartum depression symptoms.

The socioeconomic situation, social support, psychological and physical violence against pregnant women were considered to be latent variables. Socioeconomic situation, psychological violence and physical violence were investigated as first-order factorial structure. Social support was investigated as second-order factorial structure. Depressive symptoms during pregnancy were investigated as an ordinal quantitative variable and postpartum depression symptoms as a dichotomous variable.

The latent variable, socioeconomic situation, was elaborated from four indicator variables: a) maternal schooling, categorized as 4,5 to 8,9 to 11 and 12 or more years of schooling; b) the head of the family occupation, categorized as unqualified, semiqualified, qualified, office function, higher education professional level, and administrator/ manager/ director/ property owner; c) monthly family income, categorized as less than one national minimum wage (which in 2010 was R $\$ 510.00$ equivalent to US\$ $846,00), 1$ to 3,3 to 5 , and 5 or more minimum wages; and d) economic class, categorized as D/E, C and $\mathrm{A} / \mathrm{B}$ based on material ownership and the head of the family schooling level, with categories A and B having greater power of consumption.

The Associação Brasileira de Empresas de Pesquisa (Brazilian Association of Research Companies) instrument was used to measure the economic class based on the head of the family schooling level and on the use of consumer goods (color television, radio, bathroom, automobile, having a maid, washing machine, VCR or DVD, freezer and refrigerator). ${ }^{11}$

Social support was assessed using the social support scale of the Medical Outcomes Study (MOS). Social support was determined on the basis of its material dimensions (four questions), emotional/information (seven questions), affective (three questions), and positive social interaction (four questions). ${ }^{11}$ This scale has been translated and adapted to the Brazilian Portuguese language. 12,13

The Brazilian version of Questionário de Violência WHO Violence Questionnaire) was used to investigate the types of psychological and physical violence during pregnancy. This questionnaire contained questions related to psychological (6 questions), physical (6 questions) and sexual (3 questions) violence and the frequency of these events throughout the current pregnancy. The options to respond each of these 10 questions were: never, once, a few times, and many times. This question- 
naire was validated for Brazil by using data obtained from São Paulo city (1,172 women) and from 15 municipalities in the "Zona da Mata" (forest area) in Pernambuco (1,473 women) in WHO Multi-Country Study on Saúde da Mulher e Violência Doméstica contra Mulheres (Woman's Health and Domestic Violence Against Women), and further validated for the population of pregnant women in the present study. ${ }^{14}$ Sexual violence was not investigated because all the women who responded positively to one of the questions about this type of abuse had been submitted to physical violence.

To investigate psychological violence, the respondent was asked whether during the current pregnancy did anybody: a) "Insult you or made you feel bad about yourself?", b) "Belittle or humiliate you in front of other people?", c) "Do something to frighten you or scare you on purpose (e.g.: the way he looks at you, yells or breaks things)?", d) "Threaten to hurt you or somebody you like?". To investigate emotional violence, all the pregnant women who had been submitted to physical and sexual violence were excluded.

To measure physical violence, the respondent was asked whether during the current pregnancy did anybody: a) "Slap you or threw something at you that could have hurt you?", b) "Push you or shook you?", c) "Punch you or hit you with an object?", d) "Kick you, drag you or beat you up?", e) "Try to strangle you or burn you on purpose?", f) "Threaten to use or actually use a fire gun, a knife or any other type of weapon against you?".

Psychological and physical violence from any perpetrator and not only from intimate partners were included in the study.

The Depressão do Centro de Estudos Epidemiológicos (CES-D) (Epidemiologic Studies Depression Center) was developed to measure depressive symptoms in the general population based on a scale that measures the frequency of depressive symptoms during the week prior the application of the questionnaire. High scores reflect the intensity of discomfort that accompanies depression, but they are not diagnosed for depression. ${ }^{15}$

The instrument consists of 20 items. Each response may involve four grades that increase the intensity (never or rarely, sometimes, frequently, and always) corresponding the scores of $0,1,2$ and 3 ). Items 4, 8, 12 and 16 (positive) are scored with inverse grading. The final score ranges from 0 to 60 points and corresponds to the sum of the scores for all the answers. The CES-D items include questions concerning mood (items 3, 4, 6, 8, 9, 10. 12, 16, 17 and 18), psychosomatic symptoms (items 1, 5 and 11), symptoms linked to social interactions (items
14, 15 and 19), and symptoms related to motor initiative (items 2, 7, 13 and 20). 15 The final score ranges from 0 to 60 points and corresponds to the sum of the scores for all the answers, and the cut-off point of 16 is generally used to discriminate subjects with possibility of depression. 16

The depressive symptoms during pregnancy were categorized as follows: no possibility of depression (CES-D $<16$ ), moderate depressive symptoms $(\mathrm{CES}-\mathrm{D} \geq 16$ or $\leq 21)$ and severe depressive symptoms $(\mathrm{CES}-\mathrm{D} \geq 22) .16$

The Edinburgh Depression Postpartum Scale (EPDS), a validated instrument for Brazil, ${ }^{7}$ was used to assess postpartum depression symptoms after three months of childbirth. This is a self-recorded 10 -item questionnaire internationally used in the study for postpartum depression, which intends to assess the presence and the intensity of the depressive symptoms in the last 7 days using Likert-type scale from 0 to 3 . The validated version for Brazil considers a score $\geq 12$ for "depressive symptoms" this may be the most appropriate cut-off point for this context in the country with $72 \%$ sensitivity, $89 \%$ specificity and $78 \%$ predictive value. Postpartum depression symptoms were considered to be present when the sum of the scores in the Edinburgh Scale was 12 or more. 7

\section{Descriptive Analysis and Structural Equation Modeling}

Descriptive analysis for the determination of frequencies and percentages was performed by using the Stata software, version 12.0 (College Station, TX, USA). The association between violence against pregnant women and the outcome on postpartum depressive symptoms was investigated by using the Structural Equation Modeling, which is a statistical method that uses confirmatory factorial analysis and simultaneously estimates a series of regression equations, assessing direct and indirect effects on the outcome of the variables. 18

Structural Equation Modeling was carried out using the Mplus software, version 7 (Los Angeles, CA, USA). Weighted Least Square Mean and Adjusted Variance were used for the continuous and categorical variables.

The following adjusted indices were used to determine if the model presented a good adjustment: a) $p$-value more than 0.05 for the chi-square test $\left(\chi^{2}\right)$; b) $p<0.05$ and an upper limit of the $95 \%$ of confidence interval lower than 0.08 for the Root Mean Square Error of Approximation (RMSEA); c) values higher than 0.95 for the Comparative Fit Index and the Tucker Lewis Index (CFI/TLI); and d) Weighted Root Mean Residual (WRMR) values lower than 
1.17

The direct and indirect effects between variables were considered to be present when the $p$ value was less than 0.05 .

The modindexes command was used to obtain suggestions for the modification of the initial hypotheses and a new model was elaborated and analyzed if changes were considered to be theoretically acceptable.

\section{Ethical Aspects}

This study fulfilled the Resolution 196/96 criteria of the National Health Council and its complementary rules. The women were invited to participate in the study and when they agreed, they signed the written informed consent. The subject had the option to drop out of the study at any time without suffering any consequences for herself or her family during any stage of investigation. The project was approved by the Research Ethics Committee at the University Hospital - UFMA (document number 223/2009, protocol n. 4771/2008-30).

\section{Results}

Of the 1,139 pregnant women who answered the Edinburgh Questionnaire, $12.8 \%$ were up to 19 years of age and $12.1 \%$ had up to 8 years of schooling. The percentage of pregnant women belonging to $\mathrm{D} / \mathrm{A}$ economic class families and receiving less than one minimum wage was $15.5 \%$ and $4.6 \%$, respectively (Table 1).

Depressive symptoms were reported by $19.7 \%$ of the mothers 2 years after childbirth. The rates on psychological and physical violence were $47.3 \%$ and $12.1 \%$, respectively. About $20 \%$ of the women interviewed reported moderate depressive symptoms during pregnancy and $27 \%$ reported severe symptoms (Table 2).

The conceptual model showed good adjustment with no plausible suggestion of modification (Table 3). Except for the variable on the pregnant woman's schooling in the construction of the latent variable socioeconomic situation (SES), all the other factorial loads of the components on latent variables were higher than 0.5 (Table 4).

Women who suffered psychological violence during pregnancy frequently reported more postpartum depression symptoms (Standardized Coefficient, $\mathrm{SC}=0.256 ; p<0.001)$. This positive association occurred through a direct $(\mathrm{SC}=0.131$; $p=0.016)$ or an indirect $(\mathrm{SC}=0.124 ; p<0.001)$ route, the latter being mediated by depressive symptoms during pregnancy $(\mathrm{SC}=0.131 ; p<0.001)$ (Table 5).
Women submitted to physical violence during pregnancy frequently reported more postpartum depression symptoms $(\mathrm{SC}=0.221 ; p<0.001)$. This positive association only occurred by an indirect route $(\mathrm{SC}=0.126 ; p<0.001)$, with mediation of depressive symptoms during pregnancy $(\mathrm{SC}=0.126$; $p<0.001)$.

Women with depressive symptoms during pregnancy frequently presented more postpartum depression symptoms $(\mathrm{SC}=0.322 ; p<0.001)$ and reported episodes of psychological and physical violence (Table 5).

\section{Discussion}

The study of the prenatal São Luis BRISA cohort revealed that pregnant women submitted to psychological and physical violence reported depressive symptoms during pregnancy frequently reported more postpartum depression symptoms. The psychological violence association with postpartum depression symptoms occurred through direct and indirect routes, the latter was mitigated by the presence of the depression during pregnancy.

It is known that violence against pregnant women, especially if recurrent and in its severe forms, may affect the pregnant women's mental health and the women's life. It is a public health problem and a complex phenomenon whose consequences may be quite negative for the mother, fetus and child's health. 18

A longitudinal study conducted with 272 pregnant women to identify the frequency of depressive symptoms during pregnancy and to determine its association with sociodemographic, obstetric and health variables revealed that psychological violence was a risk factor for the presence of depressive symptoms during pregnancy and for postpartum depression symptoms when the main aggressors were the partner and family members. 19

However, it is important to point out that psychological violence is often unnoticed at the health services, therefore it is the less considered than the other types of violent acts. Thus, the high prevalence detected is important to sensitize health professionals, managers and researchers, as well as the victims themselves, for this type of violence and its negative repercussions on women's health, specifically regarding their mental health. 20

Women submitted to physical violence during pregnancy frequently reported more postpartum depression symptoms. This positive association occurred only in an indirect manner mediated by symptoms of depression during pregnancy. 
Table 1

Maternal socioeconomic and demographic characteristics of the prenatal BRISA cohort. São Luís - MA, 2010-2013.

\begin{tabular}{|c|c|c|}
\hline Variables & $\mathbf{N}$ & $\%$ \\
\hline \multicolumn{3}{|l|}{ Age (years) } \\
\hline Up to 19 years & 145 & 12.7 \\
\hline 20 to 24 years & 360 & 31.6 \\
\hline 25 years or more & 634 & 55.6 \\
\hline TOTAL & 1,139 & 100 \\
\hline \multicolumn{3}{|l|}{ Marital status } \\
\hline Married & 249 & 21.8 \\
\hline Consensual union & 658 & 57.7 \\
\hline Single / widow & 213 & 18.7 \\
\hline Divorced & 19 & 1.7 \\
\hline TOTAL & 1,139 & 100 \\
\hline \multicolumn{3}{|l|}{ Schooling (years)* } \\
\hline 0 to 4 years & 13 & 1.14 \\
\hline 5 to 8 years & 125 & 10.9 \\
\hline 9 to 11 years & 867 & 76.1 \\
\hline 12 or more years & 133 & 11.6 \\
\hline TOTAL & 1,138 & 100 \\
\hline \multicolumn{3}{|l|}{ Income (minimum wages)* } \\
\hline Less than 1 & 51 & 4.61 \\
\hline 1 to 3 & 615 & 55.5 \\
\hline 3 to 5 & 281 & 25.3 \\
\hline 5 or more & 160 & 14.4 \\
\hline TOTAL & 1,107 & 100 \\
\hline \multicolumn{3}{|l|}{ Pregnant woman's occupation } \\
\hline None & 787 & 51.5 \\
\hline Unqualified & 304 & 28.2 \\
\hline Semi-qualified & 459 & 42.6 \\
\hline Qualified & 51 & 4.74 \\
\hline Office functions & 166 & 15.4 \\
\hline Higher education professional level & 59 & 5.48 \\
\hline Administrators/Managers/Directors/Property Owners & 38 & 3.53 \\
\hline TOTAL & 1,077 & 100 \\
\hline \multicolumn{3}{|l|}{ CCEBa* } \\
\hline $\mathrm{D} / \mathrm{E}$ & 168 & 15.4 \\
\hline C & 747 & 68.7 \\
\hline$A / B$ & 172 & 15.8 \\
\hline TOTAL & 1,087 & 100.0 \\
\hline
\end{tabular}

a CCBE= Brazilian Economic Class Classification; *The total for each variable differed due to unknown values. 
Table 2

Maternal characteristics of BRISA prenatal cohort. São Luís - MA, 2010-2013.

\begin{tabular}{lcc}
\hline Variables & $\mathbf{N}$ & $\%$ \\
\hline Violence against women & 1,115 & 100.0 \\
No & 608 & 54.3 \\
Yes & 507 & 45.47 \\
Depressive symptoms (during pregnancy)* & 1,133 & 100.0 \\
No possibility of depression & 596 & 52.6 \\
Moderate symptoms & 228 & 20.1 \\
Severe symptoms & 309 & 27.2 \\
Depressive symptoms during postpartum period & 1,139 & 100.0 \\
With depressive symptoms & 224 & 19.7 \\
Without depressive symptoms & 915 & 80.3 \\
\hline
\end{tabular}

*The total for each variable differed due to unknown values.

Table 3

Indicators of the adjusted model. São Luís -MA, 2010-2013.

\begin{tabular}{lc}
\hline Indicators & Modela \\
\hline Chi-square $\left(\chi^{2}\right)$ & $1.507,028$ \\
Degrees of freedom & 884 \\
$p$ & $<0.001$ \\
Root Mean Square Error of Approximation & 0.025 \\
(RMSEA) & $0.023-0.027$ \\
$90 \%$ Confidence Interval & 0.990 \\
Comparative fit index (CFI) & 0.989
\end{tabular}

a Initial and final model, there was no plausible suggestion of modification. 
Standardized coefficient, standard error and $p$-values of the latent variables and the direct effects for the indicator variables. São Luís - MA, 2010-2013.

\begin{tabular}{|c|c|c|c|}
\hline Routes and Estimates & Standardized Coefficient & Standard error & $P$ \\
\hline \multicolumn{4}{|l|}{ Latent Variable } \\
\hline \multicolumn{4}{|l|}{ SES } \\
\hline Ses BY Edu & 0.463 & 0.051 & $<0.001$ \\
\hline Ses BY Occu & 0.548 & 0.045 & $<0.001$ \\
\hline Ses BY Inc & 0.684 & 0.043 & $<0.001$ \\
\hline Ses BY Class & 0.826 & 0.048 & $<0.001$ \\
\hline \multicolumn{4}{|l|}{ EMOV } \\
\hline Emov BY v1 & 0.863 & 0.040 & $<0.001$ \\
\hline Emov BY v2 & 0.886 & 0.038 & $<0.001$ \\
\hline Emov BY v3 & 0.661 & 0.045 & $<0.001$ \\
\hline Emov BY v4 & 0.655 & 0.064 & $<0.001$ \\
\hline \multicolumn{4}{|l|}{ PHYV } \\
\hline Phyv BY v5 & 0.941 & 0.033 & $<0.001$ \\
\hline Phyv BY v6 & 0.845 & 0.038 & $<0.001$ \\
\hline Phyv BY v7 & 0.907 & 0.035 & $<0.001$ \\
\hline Phyv BY v8 & 0.910 & 0.030 & $<0.001$ \\
\hline Phyv BY v9 & 0.797 & 0.108 & $<0.001$ \\
\hline Phyv BY v10 & 0.728 & 0.072 & $<0.001$ \\
\hline \multicolumn{4}{|l|}{ EDINBURGH } \\
\hline EDINBURGH BY g59_1 & 0.578 & 0.028 & $<0.001$ \\
\hline EDINBURGH BY g59_2 & 0.644 & 0.032 & $<0.001$ \\
\hline EDINBURGH BY g59_3 & 0.651 & 0.023 & $<0.001$ \\
\hline EDINBURGH BY g59_4 & 0.555 & 0.028 & $<0.001$ \\
\hline EDINBURGH BY g59_5 & 0.704 & 0.023 & $<0.001$ \\
\hline EDINBURGH BY g59_6 & 0.580 & 0.024 & $<0.001$ \\
\hline EDINBURGH BY g59_7 & 0.868 & 0.013 & $<0.001$ \\
\hline EDINBURGH BY g59_8 & 0.909 & 0.010 & $<0.001$ \\
\hline EDINBURGH BY g59_9 & 0.829 & 0.014 & $<0.001$ \\
\hline EDINBURGH BY g59_10 & 0.755 & 0.029 & $<0.001$ \\
\hline \multicolumn{4}{|l|}{ SUPP } \\
\hline Supp BY Int & 0.983 & 0.005 & $<0.001$ \\
\hline Supp BY Emoinf & 0.950 & 0.006 & $<0.001$ \\
\hline Supp BY Effe & 0.952 & 0.008 & $<0.001$ \\
\hline Supp BY Tang & 0.833 & 0.014 & $<0.001$ \\
\hline \multicolumn{4}{|l|}{ Direct Effects } \\
\hline EDINBURGH ON Ses & -0.125 & 0.043 & 0.003 \\
\hline EDINBURGH ON Supp & -0.055 & 0.036 & 0.127 \\
\hline EDINBURGH ON Emov & 0.131 & 0.054 & 0.016 \\
\hline EDINBURGH ON Phyv & 0.095 & 0.068 & 0.163 \\
\hline Supp ON Ses & 0.238 & 0.036 & $<0.001$ \\
\hline Emov ON Ses & 0.114 & 0.056 & 0.041 \\
\hline Emov ON Supp & -0.182 & 0.047 & $<0.001$ \\
\hline Phyv ON Ses & -0.025 & 0.070 & 0.721 \\
\hline Phyv ON Supp & -0.214 & 0.067 & 0.001 \\
\hline Phyv ON Emov & -0.031 & 0.017 & 0.068 \\
\hline
\end{tabular}

Ses= Socioeconomic situation, $\mathrm{BY}=$ Mplus command for obtaining the latent variable; edu= the pregnant woman's schooling level; occu= the head of the family occupation; inc= family income; class= economic class; emov= psychological violence against women during pregnancy; v1 to v4=questions number 1 to 4 about psychological violence; phyv= physical violence against women during pregnancy; v5 to v10= questions number 5 to 10 about physical violence; EDINBURGH= postpartum depression symptoms; g59_1 to g59_10=questions from EDINBURGH questionnaire; supp= social support; int= positive social interaction support; emoinf = emotional support/information; effe= affective support; tang= material support; Cesd=depressive symptoms during pregnancy; ON=Mplus command to estimate coefficient routes. The direct and indirect effects among the variables were considered present if the $p$ was less than 0.05 . 
Standardized coefficient, standard error and $p$-values of the latent variables and the direct effects for the indicator variables. São Luís - MA, 2010-2013.

\begin{tabular}{lccc}
\hline Routes and Estimates & Standardized Coefficient & Standard error & $\boldsymbol{P}$ \\
\hline Direct Effects & & & \\
EDINBURGH ON Cesd & 0.322 & 0.059 & $<0.001$ \\
Cesd ON Ses & -0.161 & 0.047 & 0.001 \\
Cesd ON Supp & -0.140 & 0.044 & 0.001 \\
Cesd ON Emov & 0.408 & 0.046 & $<0.001$ \\
Cesd ON Phyv & 0.390 & 0.053 & $<0.001$ \\
\end{tabular}

Ses= Socioeconomic situation, BY= Mplus command for obtaining the latent variable; edu= the pregnant woman's schooling level; occu= the head of the family occupation; inc= family income; class= economic class; emov= psychological violence against women during pregnancy; v1 to v4=questions number 1 to 4 about psychological violence; phyv $=$ physical violence against women during pregnancy; v5 to v10= questions number 5 to 10 about physical violence; EDINBURGH= postpartum depression symptoms; g59 1 to g59 $10=$ questions from EDINBURGH questionnaire; supp= social support; int= positive social interaction support; emoinf $=$ emotional support/information; effe= affective support; tang= material support; Cesd=depressive symptoms during pregnancy; ON= Mplus command to estimate coefficient routes. The direct and indirect effects among the variables were considered present if the $p$ was less than 0.05

\section{Table 5}

Standardized Coefficient, Standard error and p-value of the indirect effects for the indicator variables. São Luís - MA, 2010-2013.

\begin{tabular}{lcc}
\hline Routes and Estimates & Standardized Coefficient & Standard error \\
\hline Indirect Effects & & $P$ \\
Ses $\rightarrow$ EDINBURGH & & 0.039 \\
Total & -0.199 & 0.023 \\
Indirect & -0.074 & 0.001 \\
Emov $\rightarrow$ EDINBURGH & & 0.044 \\
Total & 0.256 & 0.028 \\
Indirect & 0.124 & 0.028 \\
Via Cesd & 0.131 & $<0.001$ \\
Phyv $\rightarrow$ EDINBURGH & & $<0.001$ \\
Total & 0.221 & 0.056 \\
Indirect & 0.125 & 0.029 \\
\hline
\end{tabular}

Ses=socioeconomic situation; EDINBURGH= postpartum depression symptoms; emov= psychological violence against women during pregnancy; cesd= depressive symptoms during pregnancy; phyv= physical violence against women during pregnancy. The direct and indirect effects among the variables were considered present if the $p$ was less than 0.05 . 
According to this result, a cross-sectional study conducted with 426 women from Bangladesh demonstrated a particularly strong association with postpartum depression symptoms in women submitted to physical violence before, during and after pregnancy. 21

In this present study, the depressive symptoms during pregnancy showed a direct effect on postpartum depression symptoms. In addition, the women who suffered psychological and physical violence demonstrated that those who showed depressive symptoms during pregnancy were more vulnerable to postpartum depression symptoms.

Showing the magnitude of this association, a longitudinal study on pregnant women $(n=8,323)$ conducted in England in order to study the association between depression during pregnancy and the postpartum period revealed that depression during pregnancy was the strongest risk factor for postpartum depression. 22

A systematic review confirmed this finding, showing that $41.5 \%$ of the cases of maternal depression had occurred during the gestational period, and suggested that interventions for depression should start since the prenatal period. 4

The limitations in this study were the fact that the data collection on maternal mental health was performed using instruments for mental disorders screening and not for diagnostic methods and the external validation on the findings was limited due to the use of convenience rather than a probabilistic sample. In addition, the questionnaires about violence and depression during pregnancy were applied at the same time. However, the violence instrument referred to abuse during pregnancy and the depression instrument referred to the last 7 days.

The strong points of the investigation are that this was a cohort study using international acknowledged instruments validated for Brazil and using structural equation modeling, a method that estimates a series of multiple separated regression equations and depends on one another, establishing direct and indirect linear relations among the variables. This permitted the concomitant study to interact between violence and depressive symptoms during pregnancy and postpartum depression symptoms. Most of the previous studies used bivariate or multivariable analyses by means of logistic regression, 22,23 a type of analysis that is criticized because it investigates only direct relations between explanatory variables and one result, without permitting the evaluation of intermediate routes, i.e., indirect or mediation factors. 17,24

The main and most important finding in this present research supports the evidence that depressive symptoms during pregnancy were intimately associated to psychological and physical violence during pregnancy, contributing to the onset of postpartum depression symptoms.

These findings reinforce the importance of improving women's health at reproductive age by including them in family planning programs by monitoring and educating their emotional health which may contribute in reducing possible losses in their lives.

\section{Authors' contributions}

Ribeiro SVO and Batista RFL - Design and planning of the study. Ribeiro SVO, Batista RFL and Ribeiro MRC - Analysis, interpretation of the data and writing of the manuscript. Pessoa KC, Simões VMF, Figueiredo FP and Bettiol H - Critical review. All authors approved the final version of the manuscript.

\section{References}

1. Verreault N, Da Costa D, Marchand A, Ireland K, Dritsa M, Khalifé $\mathrm{S}$. Rates and risk factors associated with depressive symptoms during pregnancy and with postpartum on set. J Psychosom Obstet Gynaecol. 2014; 35 (3): 84-91.

2. Fisher J, Mello MC, Patel V, Rahman A, Tran T, Holton S, Holmes W. Prevalence and determinants of common perinatal mental disorders in women in low- and middleincome countries: a systematic review. Organização Mundial de Saúde. 2012; 90 (2): 139-49.

3. Audi CAF, Segall-Corrêa AM, Santiago SM, Andrade MGG, Pérez-Escamilla R. Violência doméstica na gravidez: prevalência e fatores associados. Rev Saúde Pública. 2008; 42 (5): 877-85.
4. Howard LM, Oram S, Galley H, Trevillion K, Feder G Domestic violence and perinatal mental disorders: a systematic review and meta-Analysis. Plos Med. 2013; 10 (5): e1001452

5. Cox JL, Holden JM, Sagovsky R. Detection of postnatal depression. Development of the 10-item Edinburgh Postnatal Depression Scale. Br J Psychiatry. 1987; 150: 782-6.

6. Gibson J, McKenzie-McHarg K, Shakespeare J, Price J, Grey R. A systematic review of studies validating the Edinburgh Postnatal Depression Scale in antepartum and postpartum women. Acta Psychiatr Scand. 2009; 119 (5): 350-64. 
7. Santos IS, Matijasevich A, Tavares BF, Barros AJ, Botelho IP, Lapolli C, Magalhães PV, Barbosa AP, Barros FC. Validation of the Edinburgh Postnatal Depression Scale (EPDS) in a sample of mothers from the 2004 Pelotas Birth Cohort Study. Cad Saúde Pública. 2007; 23 (11): 2577-88.

8. Garcia-Esteve L, Ascaso C, Ojuel J, Navarro P. Validation of the Edinburgh Postnatal Depression Scale (EPDS) in Spanish mothers. J Affect Disord. 2003; 75 (1): 71-6.

9. Uwakwe R, Okonkwo JE. Affective (depressive) morbidity in puerperal Nigerian women: validation of the Edinburgh Postnatal Depression Scale. Acta Psychiatr Scand. 2003; 107 (4): 251-9

10. IBGE (Instituto Brasileiro de Geografia e Estatística) Cidades. [acesso em 02 nov 2014]. Disponível em: https://cidades.ibge.gov.br/brasil/ma/sao-luis/panorama

11. ABEP (Associação Brasileira de Empresas de Pesquisa). Critério de Classificação Econômica Brasil 2012. [Internet]. São Paulo, SP: ABEP; 2015 [acesso em 20 jun 2015]. Disponível em: http://www.abep.org/Servicos/ Download.aspx?id=01.

12. Chor D, Gríep RH, Lopes CS, Faerstein E. Medidas de rede e apoio social no Estudo Pró-Saúde: pré-testes e estudo piloto. Cad Saúde Pública. 2001; 17 (4): 887-96.

13. Faerstein E, Chor D, Lopes CS, Werneck GL. Estudo PróSaúde: características gerais e aspectos metodológicos. Rev Bras Epidemiol. 2005; 8 (4): 454-66.

14. Schraiber LB, Latorre MRDO, França Jr I, Segri NJ, D'Oliveira AFPL. Validade do instrumento WHO VAW para estimar violência de gênero contra a mulher. Rev Saúde Pública. 2010; 44 (4): 658-66.

15. Flach C, Leese M, Heron J, Evans J, Feder G, Sharp D, Howard LM. Antenatal domestic violence, maternal mental health and subsequent child behaviour: a cohort study. BJOG. 2011; 118 (11): 1383-91.
16. Fernandes RCL, Rozenthal M. Avaliação da sintomatologia depressiva de mulheres no climatério com a escala de rastreamento populacional para depressão CES-D. Rev Psiquiatr RS. 2008; 30 (3): 192-200.

17. Kline RB. Principles and practice of structural equation modeling. New York: The Guilford Press; 2016.

18. Fonseca-Machado MO. Violência na gestação e saúde mental de mulheres que são vítimas de seus parceiros [tese]. Ribeirão Preto: Escola de Enfermagem de Ribeirão Preto, Universidade de São Paulo; 2014.

19. Lima MOP, Tsunechiro MA, Bonadio IC, Murata M. Sintomas depressivos na gestação e fatores associados: estudo longitudinal. Acta Paul Enferm. 2017; 30 (1): 39-46.

20. Ludermir AB, Lewis G, Valongueiro SA, de Araújo TV, Araya R. Violence against women by their intimate partner during pregnancy and postnatal depression: a prospective cohort study. Lancet. 2010; 376 (9744): 903-10.

21. Heron J, O'Connor TG, Evans J, Golding J, Glover V, ALSPAC Study Team. The course of anxiety and depression through pregnancy and postpartum in a community sample. J Affect Disord. 2004; 80 (1): 65-73.

22. Taillieu TL, Brownridge DA. Violence against pregnant women: prevalence, patterns, risk factors, theories, and directions for future research. Aggression and Violent Behavior. 2010; 15 (1): 14-35.

23. Shamu S, Abrahams N, Temmerman M, Musekiwa A, Zarowsky C. A systematic review of African studies on intimate partner violence against pregnant women: prevalence and risk factors. PLoS One. 2011; 6 (3): e17591.

24. Wang J, Wang X. Structural equation modeling: applications using Mplus. Noida: Thomson Digital; 2012.
Received on February 22, 2018

Final version presented on December 02, 2018

Approved on January 31, 2019 